\title{
Investigation of the Properties of High-Density Polyethylene Pipes used in Kurdistan for Piping System of Potable Water
}

\author{
Sarkawt Rostam \\ Department of Mechanical Engineering/ Production \\ College of Engineering \\ Sulaimani Polytechnic University \\ Sulaimani, Iraq \\ sarkawt.rostam@spu.edu.iq
}

\begin{tabular}{l} 
Article Info \\
Volume 6-Issue 2- \\
December 2021 \\
DOI: \\
10.24017/science.2021.2.16 \\
Article history: \\
Received 8/11/2021 \\
Accepted 26/1/2022 \\
\hline
\end{tabular}

\section{Keywords:}

Polyethylene pipes, mechanical properties, induction time, glass transition temperature. differential scanning calorimetry, oxidation

\begin{abstract}
High-density polyethylene (HDPE) pipes are recently used in the water distribution network in Kurdistan to replace the old pipes. In this investigation, two types of HDPE pipes (namely A and $B$ ) available in the local market have been studied and their properties were compared. Mechanical properties through tensile tests have been investigated and valuable data were collected that could provide a guideline reference for the designers and end-users utilizing these pipes for water supply networks. Furthermore, the HDPE samples were analyzed by differential scanning calorimetry (DSC). Results showed that the ultimate tensile strength recorded for pipe $B$ was greater than pipe $A$ by $8 \%$. Besides, both the elongation at break and strain at break for pipe A was outperformed by almost 6\%. On the other hand, the tests showed that the transition from elasticity behavior to ductility behavior for pipe B occurs earlier in comparison to pipe A. It was noted from the gathered information that the two tested pipes were within the standards with variations in their characteristics.
\end{abstract}

Copyright $($ C) 2021Kurdistan Journal of Applied Research. All rights reserved.

\section{INTRODUCTION}

High-density polyethylene pipes are extremely used for water, gas, and sewage systems and are of yearly increased demand. Recently, PE pipes are widely used in piping water [1] and gas systems due to their superior properties of low cost, excellent mechanical and chemical properties [2-4], long-term resistance to environmental effects, and ease of installation as well as lower weight, high resistance to corrosion and ease of joining. Conversely, the repair and technical efforts are of high costs. So, it is necessary to study the reliability of these pipe systems [5-8]. 
The lifetime of plastic pipes used in water and gas supply is estimated to be of 50 years. For this long time of usage, various tests to prove the usability and reliability of these pipes are crucial to avoid high costs of failure during installation and repair during the service [9].

Tensile behavior of recycled HDPE was studied by Ries et al. [10]. The tests were conducted at room temperature for different strain rates. Three stress-strain curves were used to identify the material parameters that can be used in engineering problems. The results show a significant effect of strain rate on ductility, modulus of elasticity, and tensile strength of HDPE. Tensile and oxidation induction time tests were conducted by Castagnetti et al. [11] to show the effect of chlorinated and non-chlorinated water on HDPE pipes used in urban networks for water conveyance. The tests show that the mechanical properties were not affected by the chlorine oxide for the duration of exposure up to $2000 \mathrm{hrs}$. Draghicescu et al. [12] presented results of tensile tests for HDPE pipelines used for water supply networks to characterize their mechanical properties. It is shown that an increase of Young's modulus and stiffness depends on the pipe's diameter. Wu et al. [13] studied the mechanical behavior through the uniaxial tensile test of buried PE pipe under load subsidence. They proposed that the results could be used as a reference for safety and maintenance strategy for the used pipes during service.

A predictive model to predict the lifetime of PE pipes was proposed by Wang et al. [14] using the oxidative induction time (OIT) test. The results showed that the internal pressure has a direct impact on the PE pipes. Wu et al. [15] developed a finite element model to analyze the factors affecting the strength of PE pipes. Their results showed that both the strain rate and transition section length have a significant effect on the pipe's strength.

Kratochvilla el al. [16] use a cracked round bar to characterize two types of PE pipes namely PE 100 and PE 100-RC (resistance to crack). The results were evaluated by comparing them to other tests such as notched pipe, creep, and Charpy impact tests.

Mechanical properties of polyethylene-layered silicate nanocomposites studied by Alexandre et al. [17]. The study showed that the tensile and shear properties (including Young's modulus, shear modulus, and strain behavior) were improved by the addition of hydrogen. In addition to mechanical properties, Frank et al. [5] investigate the morphology, stabilization, and structure of materials used in PE pipes. The focus was on the remaining lifetime of the pipes used in gas and water distribution systems. To assess the reliability levels of HDPE pipes, Khelif et al. [6] present a probabilistic characterization of this pipe and its lifetime. Their analysis showed that the influence of the operating temperature of the used pipes on the pipe safety was larger than the gas pressure fluctuations.

Expanding the findings from previous works on the mechanical properties of PE pipes leads to practical recommendations and guides for dealing with such pipes in field conditions.

In this paper, mechanical properties through tensile test and response to heat through thermal oxidation resistance using DSC for HDPE pipes were investigated experimentally. The aim of this investigation is to gather data about the HDPE pipes available in local markets and used in the area for potable water distribution networks. This is to ensure reliable and safe use of the pipes within the granted period given by the manufacturers as their repair and maintenance are of high costs. The outcomes from this investigation supply the designer, as well as the users with valuable data about HDPE pipes used in water distribution networks, were the research covered the outputs of tensile tests for different samples taken from the two investigated types of HDPE pipes such as tensile strength and its corresponding strain, elongation at break, and elongation at yield and they were compared within the ISO standard of PE pipes used for the piping system of potable water. In addition, the research covered the values of glass transition temperature and time, and oxidation induction time from the DSC test.

\section{METHODS AND MATERIALS}

\subsection{Materials}

The high-density polyethylene black with blue strip pipes has been used in the tests. They were provided by the local market for two manufacturers providing the market with PE pipes 
and used in the piping system of potable water. Through this paper, the two manufacturers are named "A" and "B". The pipes specifications are listed in Table 1. As is clear from the table that the type of pipes used is PE 100 from manufacturer " $A$ " while manufacturer " $B$ " uses the type which has resistance to crack and is called PE 100-RC. Other specifications are the same as explained in the table.

Table 1: Specifications of PE pipes

\begin{tabular}{lll}
\hline Specifications & Manufacturer A & Manufacturer B \\
\hline Type & PE 100 & PE 100-RC \\
\hline $\begin{array}{l}\text { Outside diameter } \mathbf{x} \text { wall } \\
\text { thickness }\end{array}$ & $110 \times 10(\mathrm{~mm})$ & $110 \times 10(\mathrm{~mm})$ \\
\hline Nominal pressure (PN) & 16 bars & 16 bars \\
\hline Standard dimension ratio (SDR) & 11 & 11 \\
\hline Standard & ISO 4427 & ISO 4427 \\
\hline Color & Black with blue strips & Black with blue strips \\
\hline Usage & Potable water supply & Potable water supply \\
\hline
\end{tabular}

\subsection{Sample preparation for tensile test}

Pieces of $220 \mathrm{~mm}$ length were prepared from pipes of $110 \mathrm{~mm}$ diameter and $10 \mathrm{~mm}$ wall thickness. From the prepared pieces, PE testing samples with a cross-sectional area of $10 \times 10$ $\mathrm{mm}$ were cut according to ISO 6259-3 using a computerized numerical (CNC) milling machine (Figure 1).

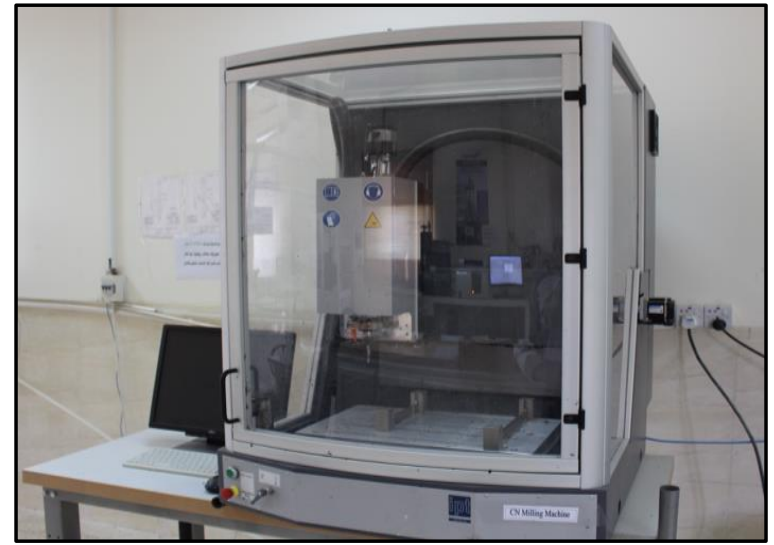

Figure 1: CNC milling machine for sample preparation

Figure 2 and Table 2 show the dimensions of the testing sample.

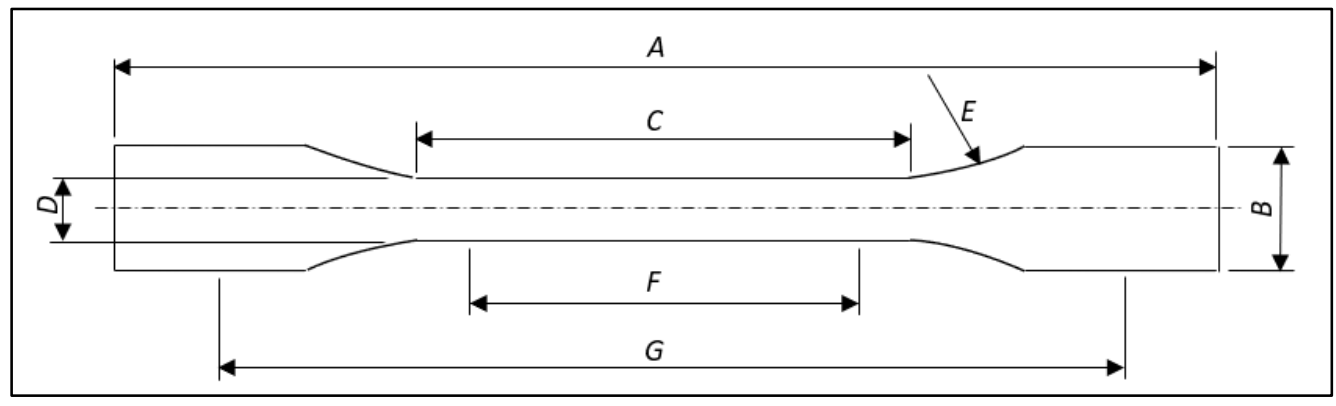

Figure 2: PE test pieces according to ISO 6259-3 
Table 2: Dimensions of test specimens according to ISO 6259-3

\begin{tabular}{lll}
\hline Symbol & Description & Dimension, $\mathbf{~ m m}$ \\
\hline $\mathbf{A}$ & Overall length (minimum) & 150 \\
\hline B & Width of ends & $20 \pm 0.2$ \\
\hline $\mathbf{C}$ & Length of narrow, parallel-sided portion & $60 \pm 0.5$ \\
\hline $\mathbf{D}$ & Width of narrow, parallel-sided portion & $10 \pm 0.2$ \\
\hline $\mathbf{E}$ & Radius & 60 \\
\hline $\mathbf{F}$ & Gauge length & $50 \pm 0.5$ \\
\hline $\mathbf{G}$ & Initial distance between grips & $115 \pm 0.5$ \\
\hline
\end{tabular}

\subsection{Mechanical test}

The tensile samples of high-density PE pipes were tested using universal machine test (Testometric- $50 \mathrm{kN}$, Figure 3) according to ISO 6259. Three samples from each manufacturer (A and $\mathrm{B}$ ) were taken from the pipes and cut by a CNC milling machine into the shape as shown previously in Figure 2. The samples were designated as PE-A1, PE-A2, PE-A3, PE-B1, PE-B2, and PE-B3. Force, stress, strain, and elongation at different stages were being measured.

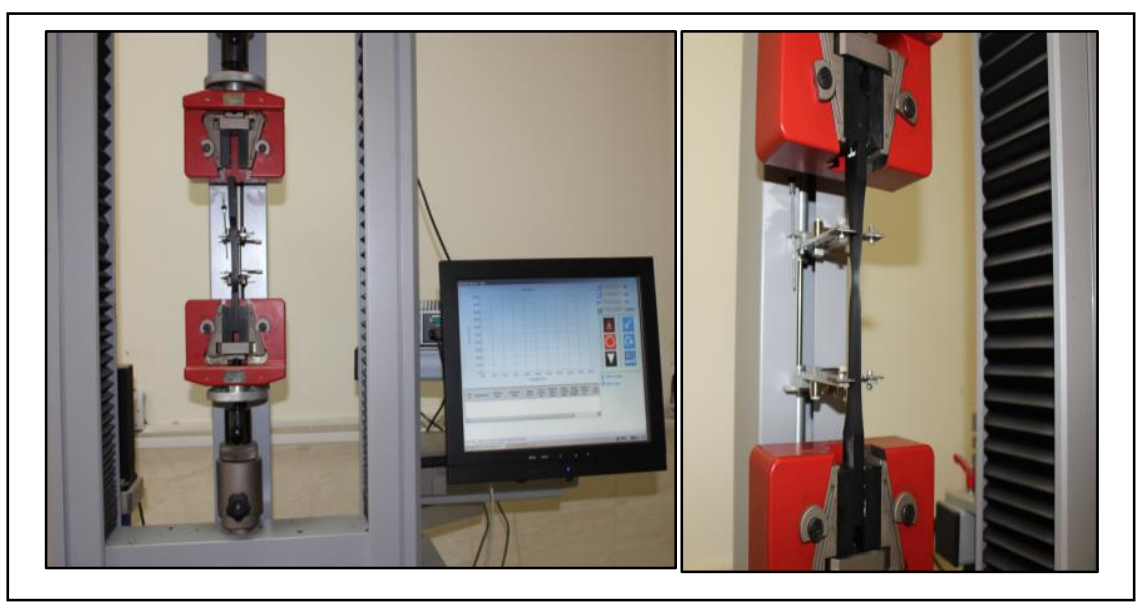

Figure 3: Universal machine test

\subsection{Differential Scanning Calorimetry test}

The response of PE pipes to heat was investigated through differential scanning calorimetry (DSC). In this work, the device of DSC 200-F3 type has been used (Figure 4). It contains two pans in its measurement chamber. The first pan is filled with punched samples of PE pipes for both A and B manufacturers in separate tests and the other pan, which is called the reference pan remains empty. The change of the temperature rate within the time of experimentation is monitored through a connected computer to the DSC device. The oxidation induction time (OIT), glass transition, and other related indicators for each pipe were measured. The input parameters for experiments are shown in Table 3. 


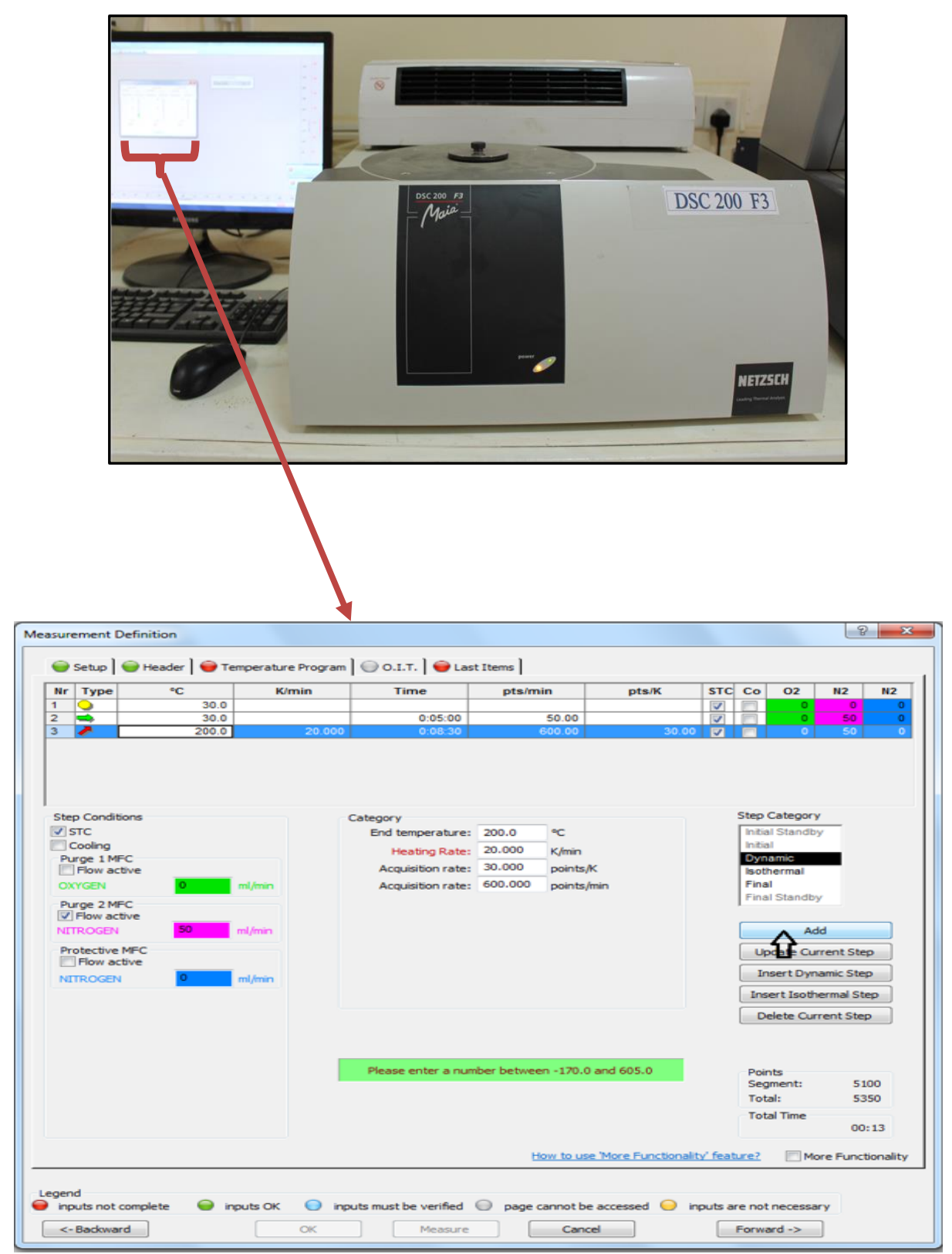

Figure 4: Differential scanning calorimetry

Table 3: Input parameters to DSC 200-F3

\begin{tabular}{ll}
\hline Parameter & Value \\
\hline Material & PE \\
\hline PE sample mass & $15 \mathrm{mg}$ \\
\hline Reference mass & $0 \mathrm{mg}$ \\
\hline Crucible mass & $23 \mathrm{mg}$ \\
\hline
\end{tabular}




\begin{tabular}{ll}
\hline Purge 1 & Oxygen \\
\hline Purge 2 & Nitrogen \\
\hline Protective purge & Nitrogen \\
\hline Start temperature & $30^{\circ} \mathrm{C}$ \\
\hline End temperature & $200^{\circ} \mathrm{C}$ \\
\hline Emergency reset temperature & $210^{\circ} \mathrm{C}$ \\
\hline Heating rate & $20 \mathrm{~K} / \mathrm{min}$ \\
\hline Nitrogen flow rate & $50 \mathrm{ml} / \mathrm{min}$ \\
\hline Oxygen flow rate & $50 \mathrm{ml} / \mathrm{min}$ \\
\hline
\end{tabular}

\section{RESULT AND DISCUSSION}

\subsection{Tensile test results}

Samples of high-density PE-100 pipes from two different manufacturers have been tested using a universal machine test. The conditions of the conducted experiments are pretension of $10 \mathrm{~N}$, gauge length of $50 \mathrm{~mm}$, sample length of $220 \mathrm{~mm}$, and a test speed of $50 \mathrm{~mm} / \mathrm{min}$.

Figures 5 and 6 show the stress-strain curve for the two types of PE pipes under investigation. As it appears from the curves that the PE specimen reaches the upper yield point which gives ultimate tensile stress and then an elastic extension can be shown until it reaches its breakpoint giving maximum strain at break. The tensile test is usually used to show the mechanical behavior of thermoplastics. The results from such a test are used to find out the ultimate strength, applied load at peak, yield strength, strain, elongation at yield, elongation at LOP, and elongation at break. The test conditions are highly affecting the behavior of the thermoplastics so the results from the tensile test can provide a behavior index during the usage of the pipes. 


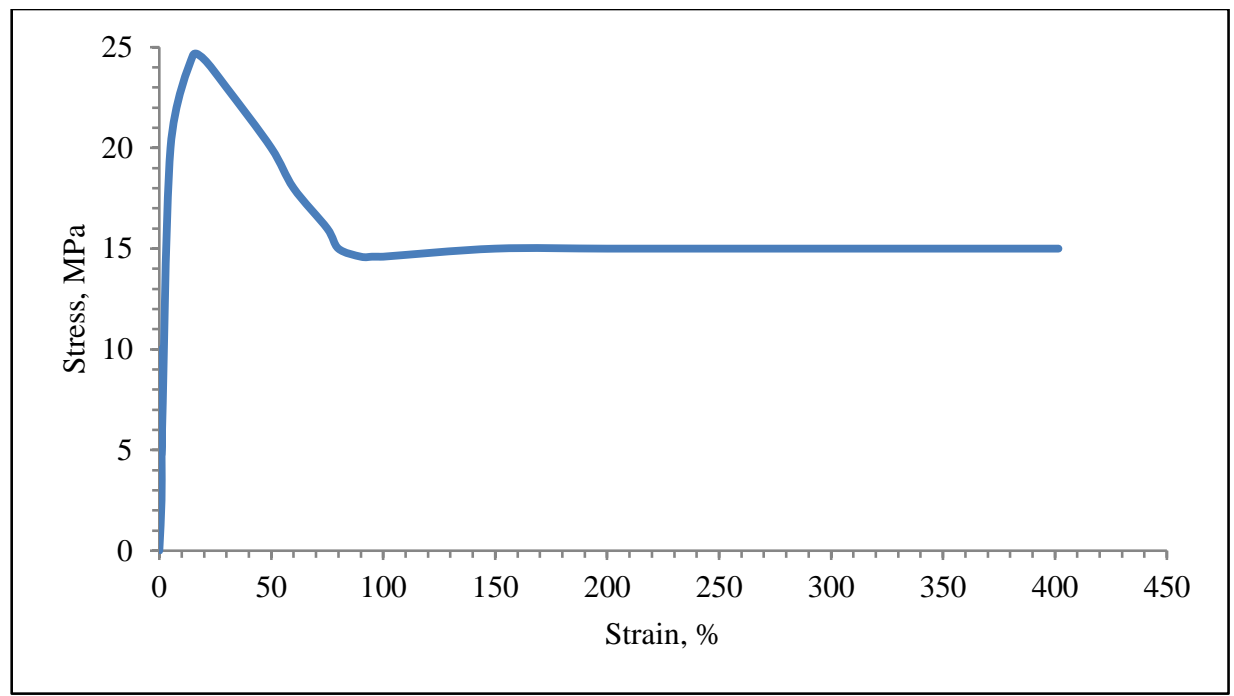

Figure 5: Stress-strain diagram for sample PE-A1

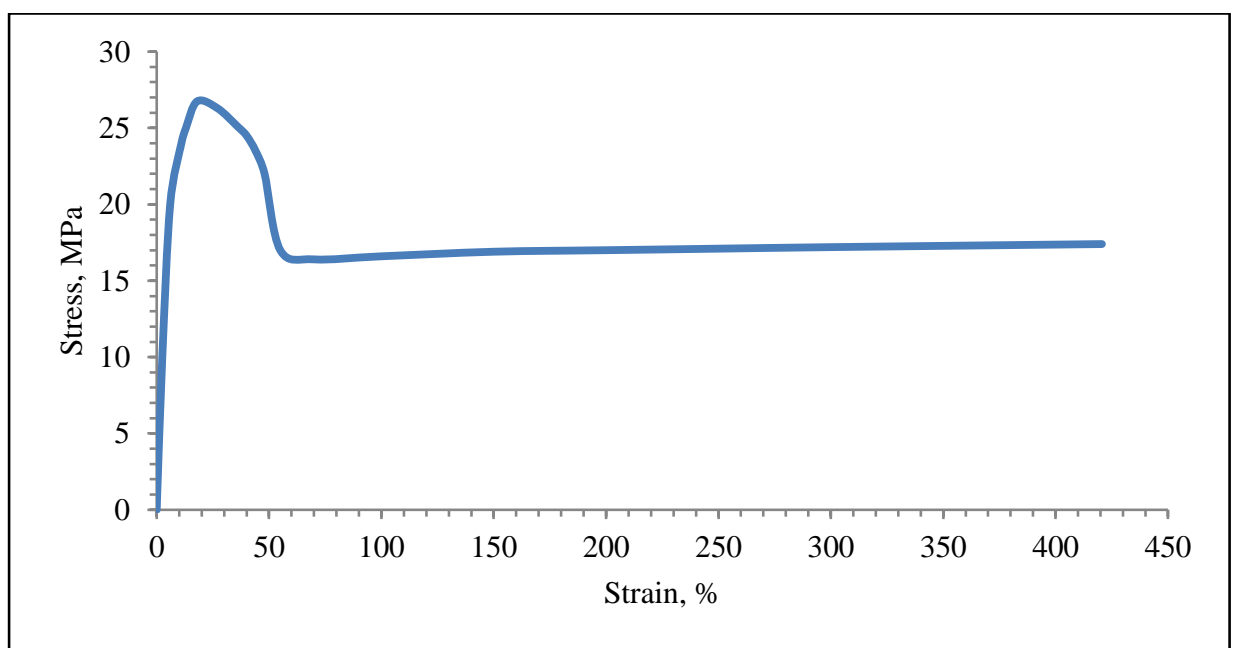

Figure 6: Stress-strain diagram for sample PE-B2

Table 4 summarizes the results of tensile strength and the corresponding strain. It is clear from the table that the pipe from manufacturer "B" gives higher strength in comparison to the one from manufacturer "A" by almost $8 \%$.

Table 4: Ultimate tensile strength and corresponding strain from the tensile test

\begin{tabular}{lll}
\hline Sample & $\begin{array}{l}\text { Ultimate tensile strength } \\
(\mathbf{M P a})\end{array}$ & $\begin{array}{l}\text { Strain } \\
\%\end{array}$ \\
\hline PE-A1 & 24.59 & 20 \\
\hline PE-B2 & 26.75 & 18 \\
\hline
\end{tabular}

The relationship between force and elongation for the PE tested samples of manufacturer A is shown in Figure 7 and for a manufacturer B is shown in Figure 8. Both figures show that the maximum applied load is between 2379 - $2459 \mathrm{~N}$ for PE-A samples and $2524-2675 \mathrm{~N}$ for PE-B. These values are corresponding to elongation at break as follows: from 200.855 $314.07 \mathrm{~mm}$ and from 201.810 - $306.806 \mathrm{~mm}$ for PE-A and PE-B samples respectively. 


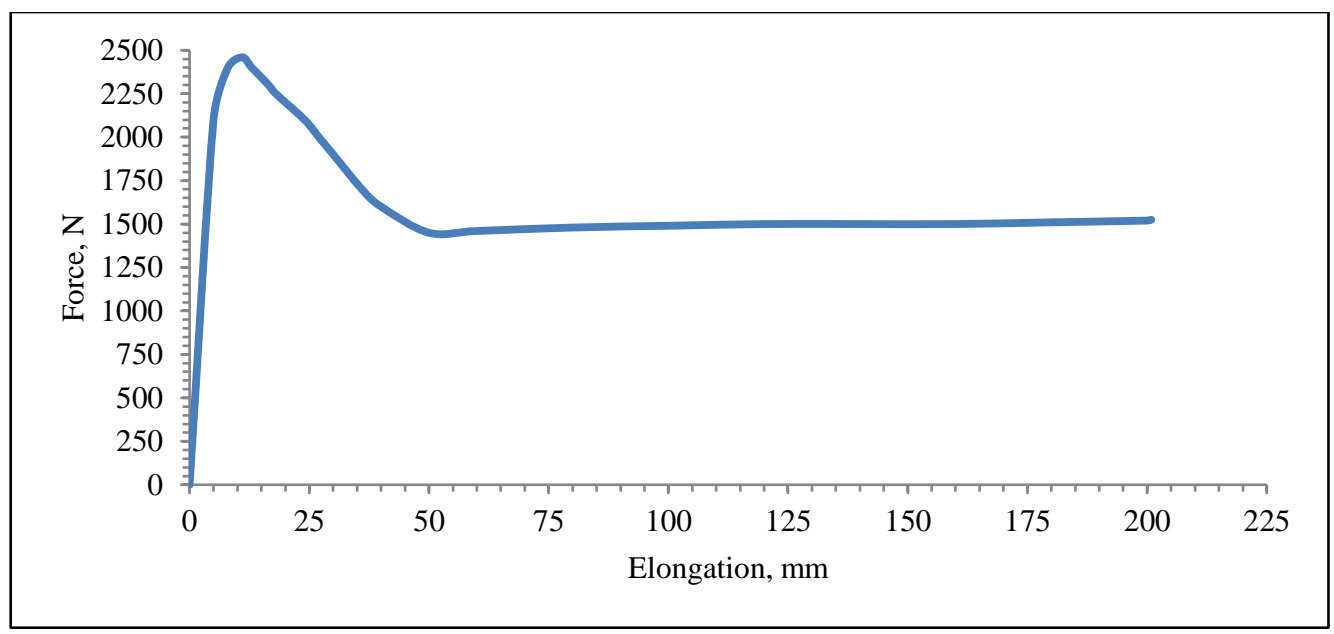

(a)PE-A1

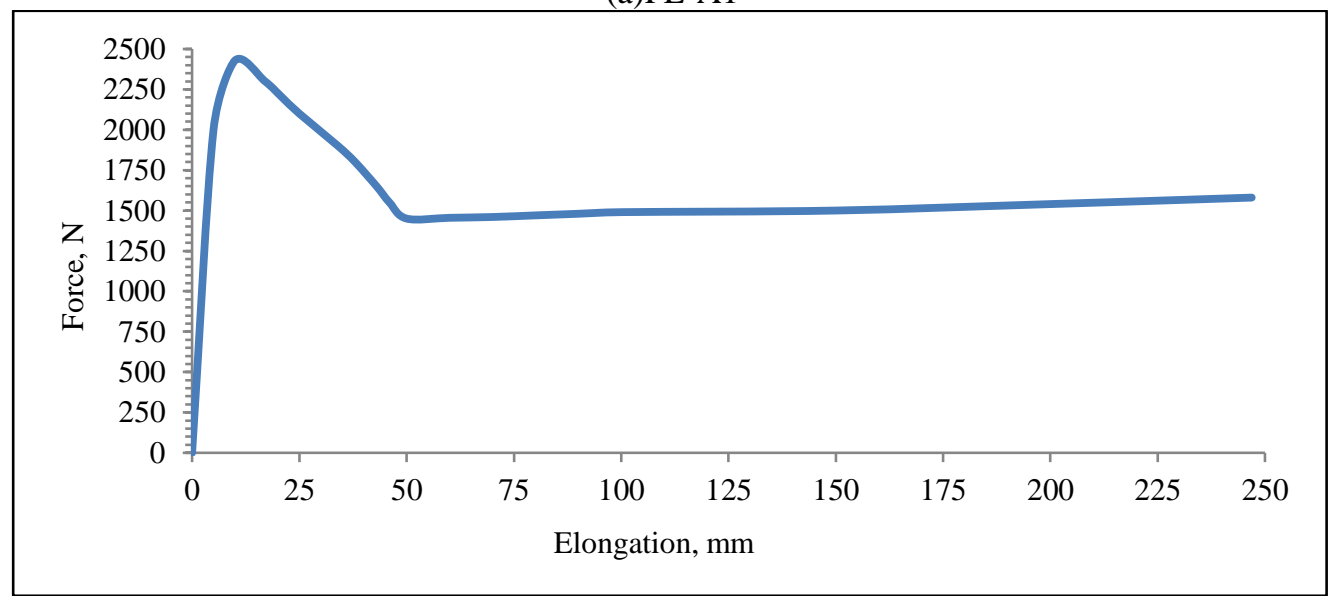

(b)PE-A2

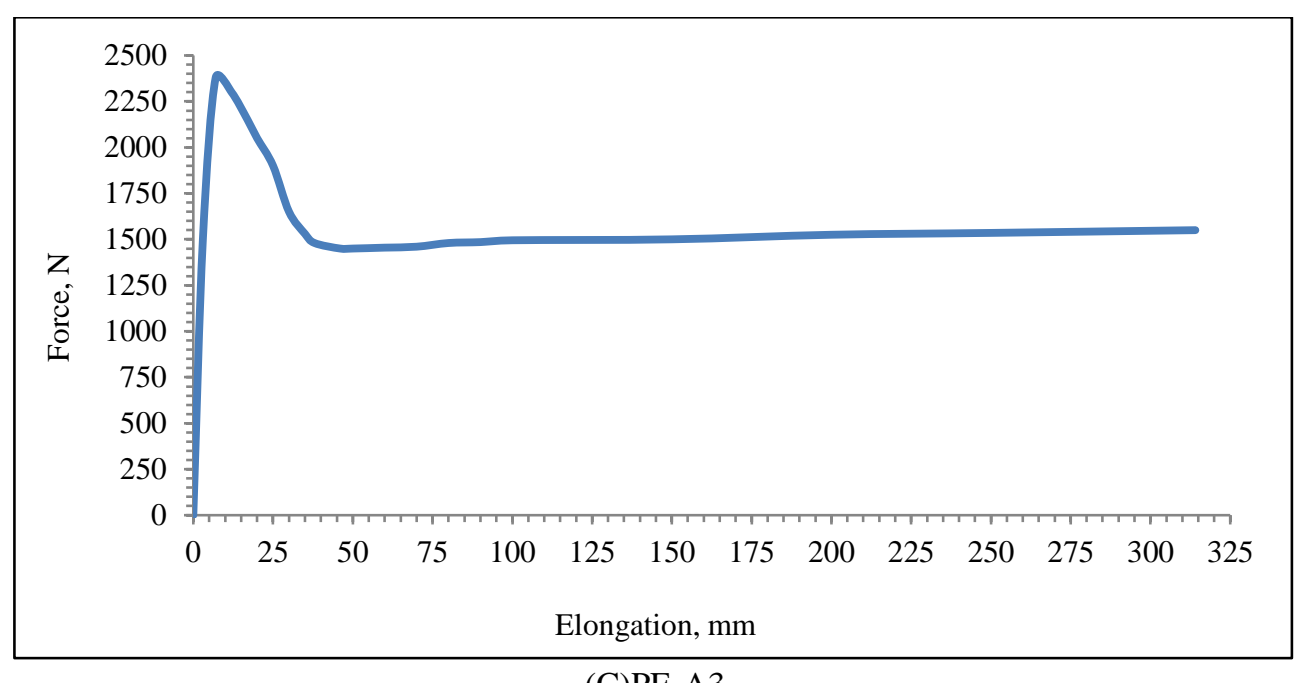

Figure 7: Force-elongation relationship for samples PE-A 


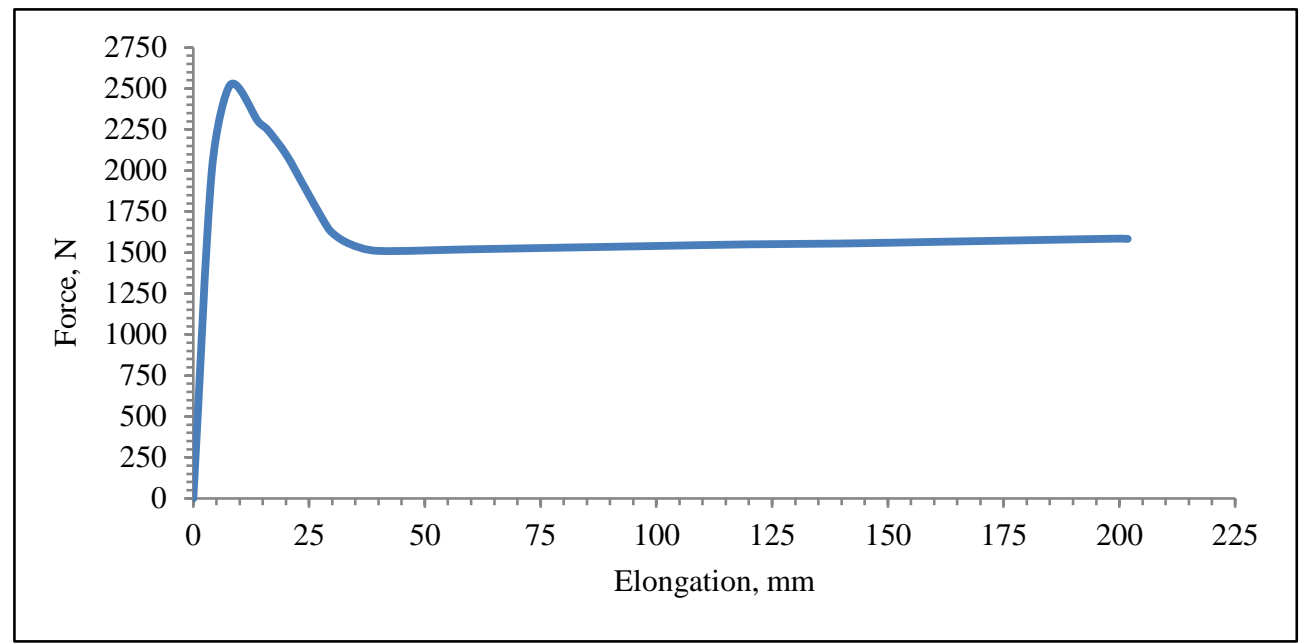

(a)PE-B1

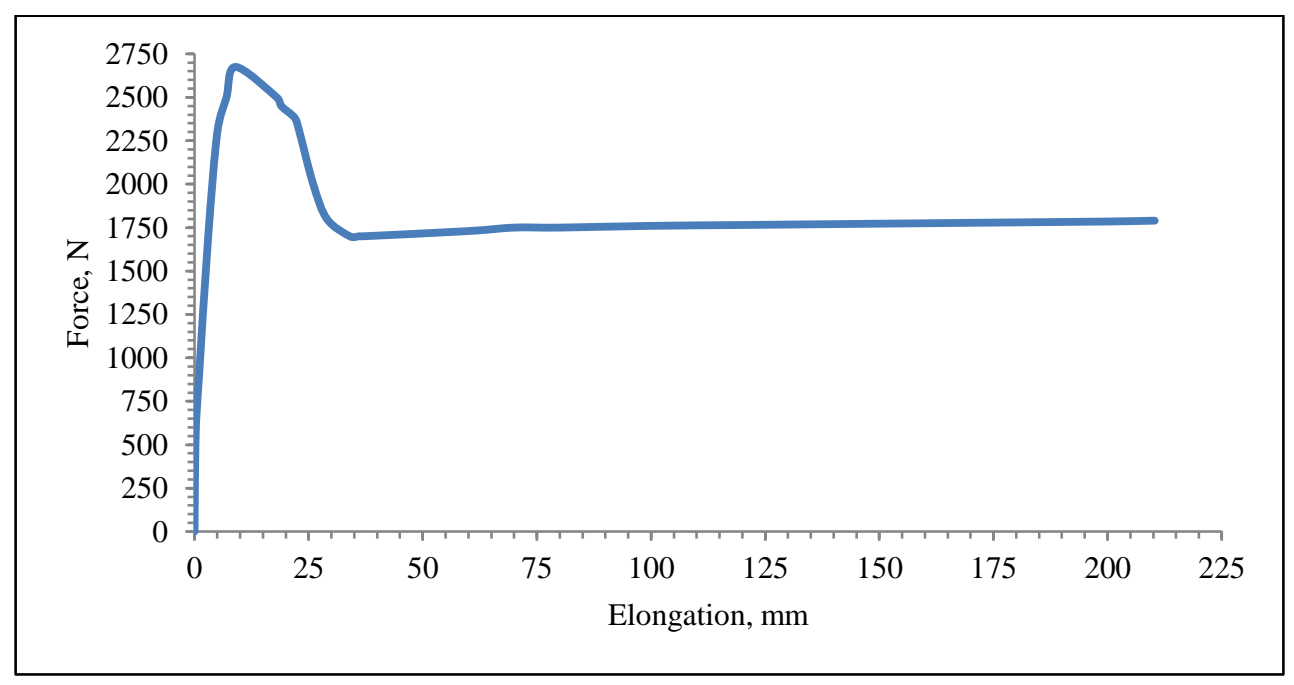

(b)PE-B2

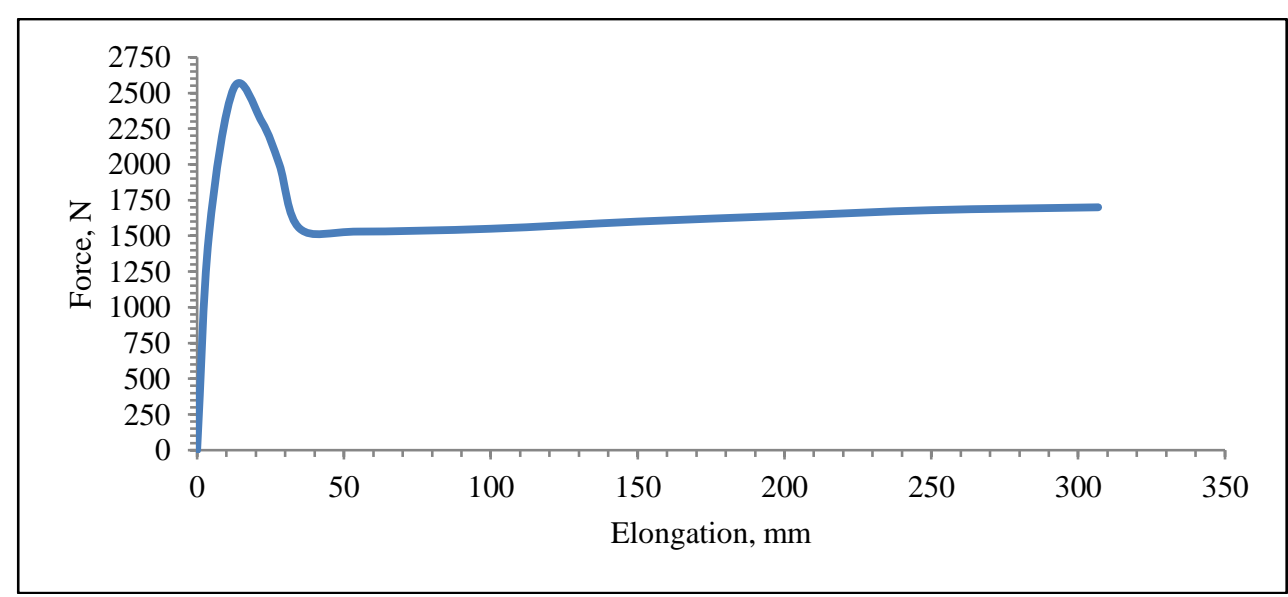

(C)PE-B3

Figure 8: Force-elongation relationship for samples PE-B 
To calculate the elongation at break as a percentage value, the following formula is used:

$\varepsilon=\frac{l-l_{o}}{l_{o}} \times 100 \%$

Where:

$\varepsilon=$ elongation at break as a percentage value,

$l=$ gauge length at break, $\mathrm{mm}$

$l o=$ initial gauge length, $\mathrm{mm}$.

By applying the above formula and using the values of elongation at break in $\mathrm{mm}$ from Figures 7 and 8 above, Table 5 can be drawn. The last two columns of the table showed that the elongation at break for all tested specimens is within the standard value of ISO 4427-2 ( $\geq$ $350 \%)$.

Table 5: Results of elongation at break for the tested samples

\begin{tabular}{llll}
\hline Sample & $\begin{array}{l}\text { Elongation at break } \\
\text { mm }\end{array}$ & $\begin{array}{l}\text { Elongation at break } \\
\%\end{array}$ & $\begin{array}{l}\text { Elongation at break, \% } \\
\text { According to ISO 4427-2 }\end{array}$ \\
\hline PE-A1 & 200.855 & 401.710 \\
\cline { 1 - 2 } PE-A2 & 246.916 & 493.832 & \\
\cline { 1 - 2 } PE-A3 & 314.070 & 628.140 & \multirow{2}{*}{$\geq 350 \%$} \\
\hline PE-B1 & 201.810 & 403.620 & \\
\hline PE-B2 & 210.320 & 420.640 \\
\hline PE-B3 & 306.806 & 613.806 \\
\hline
\end{tabular}

As a summary of the results recorded from the tensile test, Table 6 was prepared as a guide table for designers and end-users of the investigated pipes. The table shows that the values of elongation at break, elongation at yield, and strain at break for the PE-A group outperform while the values of force at peak and elongation at LOP for the PE-B group outperform. Therefore, the designer has the right to choose the preferred PE pipe (A or B manufacturer) depending on the requirements during the pipe installation in water networks.

Table 6: Results from tensile tests

\begin{tabular}{|c|c|c|c|c|c|c|c|c|c|}
\hline 劳 & 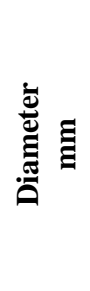 & 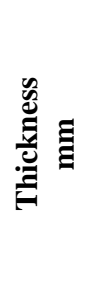 & 忢 & $\overbrace{}^{\mathbb{Z}}$ & 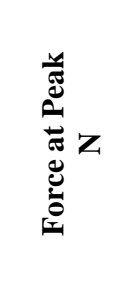 & 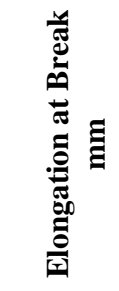 & 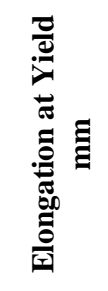 & 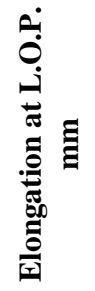 & 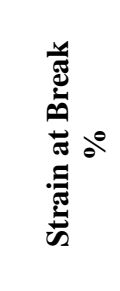 \\
\hline PE-A1 & 110 & 10 & 10 & 100 & 2459 & 200.855 & 8.735 & 0.865 & 401.586 \\
\hline PE-A2 & 110 & 10 & 10 & 100 & 2429 & 246.916 & 8.276 & 0.686 & 493.792 \\
\hline PE-A3 & 110 & 10 & 10 & 100 & 2379 & 314.070 & 8.350 & 0.590 & 628.014 \\
\hline Average & & & & & 2422.33 & 253.94 & 8.453 & 0.713 & $\mathbf{5 0 7 . 7 9}$ \\
\hline PE-B1 & 110 & 10 & 10 & 100 & 2524 & 201.810 & 7.860 & 0.730 & 403.539 \\
\hline PE-B2 & 110 & 10 & 10 & 100 & 2675 & 210.320 & 8.500 & 0.800 & 420.640 \\
\hline PE-B3 & 110 & 10 & 10 & 100 & 2535 & 306.806 & 7.686 & 0.656 & 613.563 \\
\hline Average & & & & & 2578 & 239.64 & 8.015 & 0.728 & 479.24 \\
\hline
\end{tabular}




\subsection{DSC test results}

Figure 9- 12 shows the glass transition for polymer under investigation where the mechanical properties of PE-100 change from elastic material to brittle material. Figures 9 and 10 show the glass transition temperature (Tg) for PE-A and PE-B samples respectively. While Figure 11 and 12 shows the time required for this transition.

To get a clear view of the Tg values for the investigated samples from both manufacturers A and $\mathrm{B}$, Figure 13 has been drawn. The figure illustrates that from the onset to the end, the transition of PE-A $\left(126.8^{\circ} \mathrm{C}-137.1^{\circ} \mathrm{C}\right)$ is above that for PE-B $\left(119.1^{\circ} \mathrm{C}-133.6^{\circ} \mathrm{C}\right)$. Regarding the transition time, this time for the pipe of manufacturer $\mathrm{A}$ starts from $146.8 \mathrm{~min}$ and ends at $163.7 \mathrm{~min}$ while for manufacturer B starts at $119.3 \mathrm{~min}$ and ends at $128.2 \mathrm{~min}$. This explains that the transition from elasticity behavior to ductility behavior for pipe B occurs earlier in comparison to pipe A.

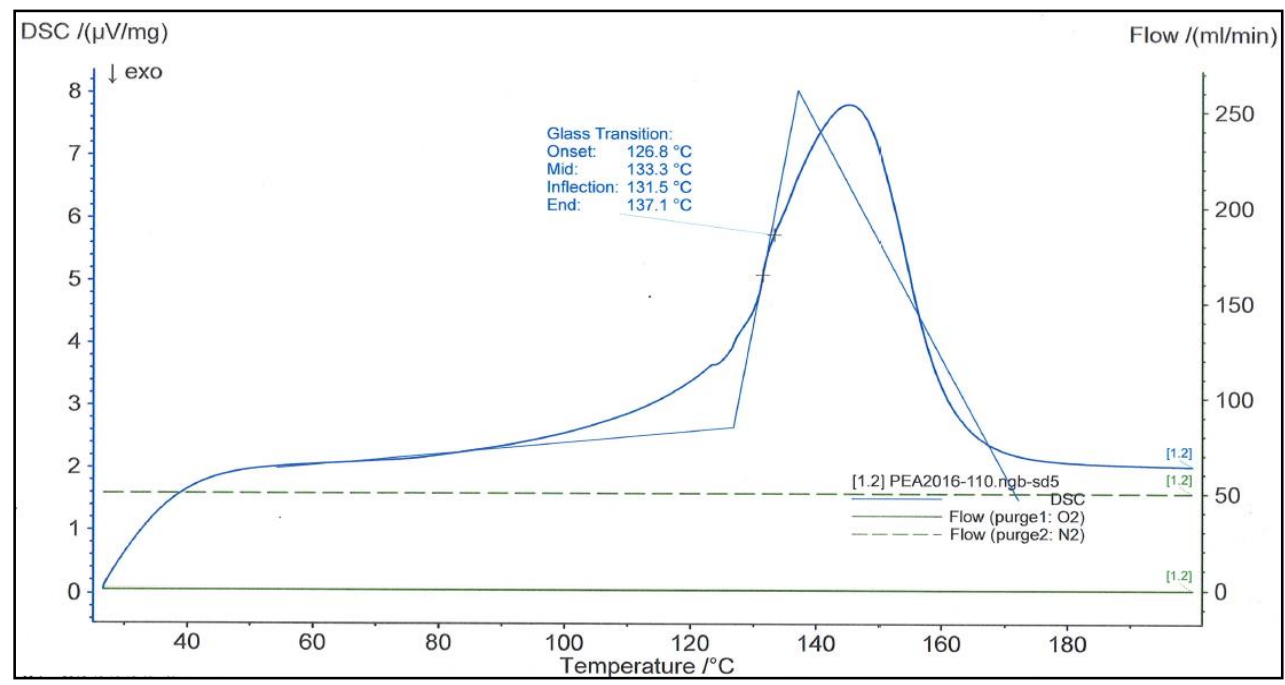

Figure 9: Glass transition temperatures for PE-A samples

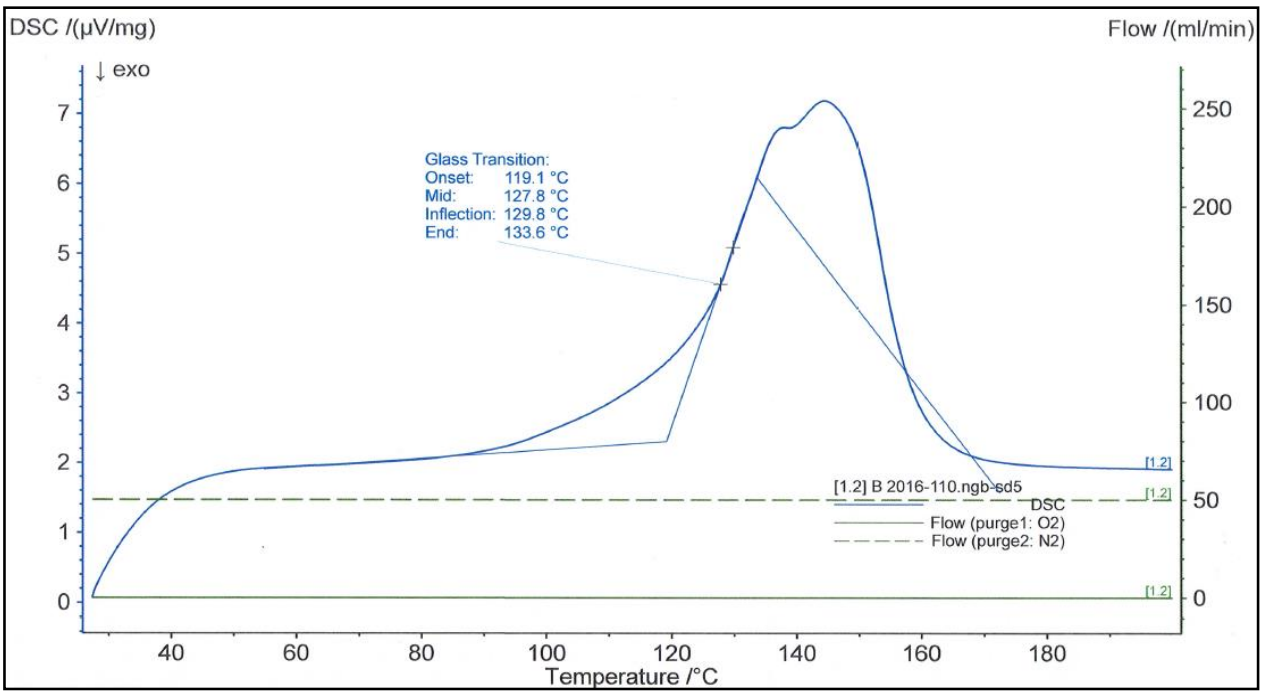

Figure 10: Glass transition temperatures for PE-B samples 


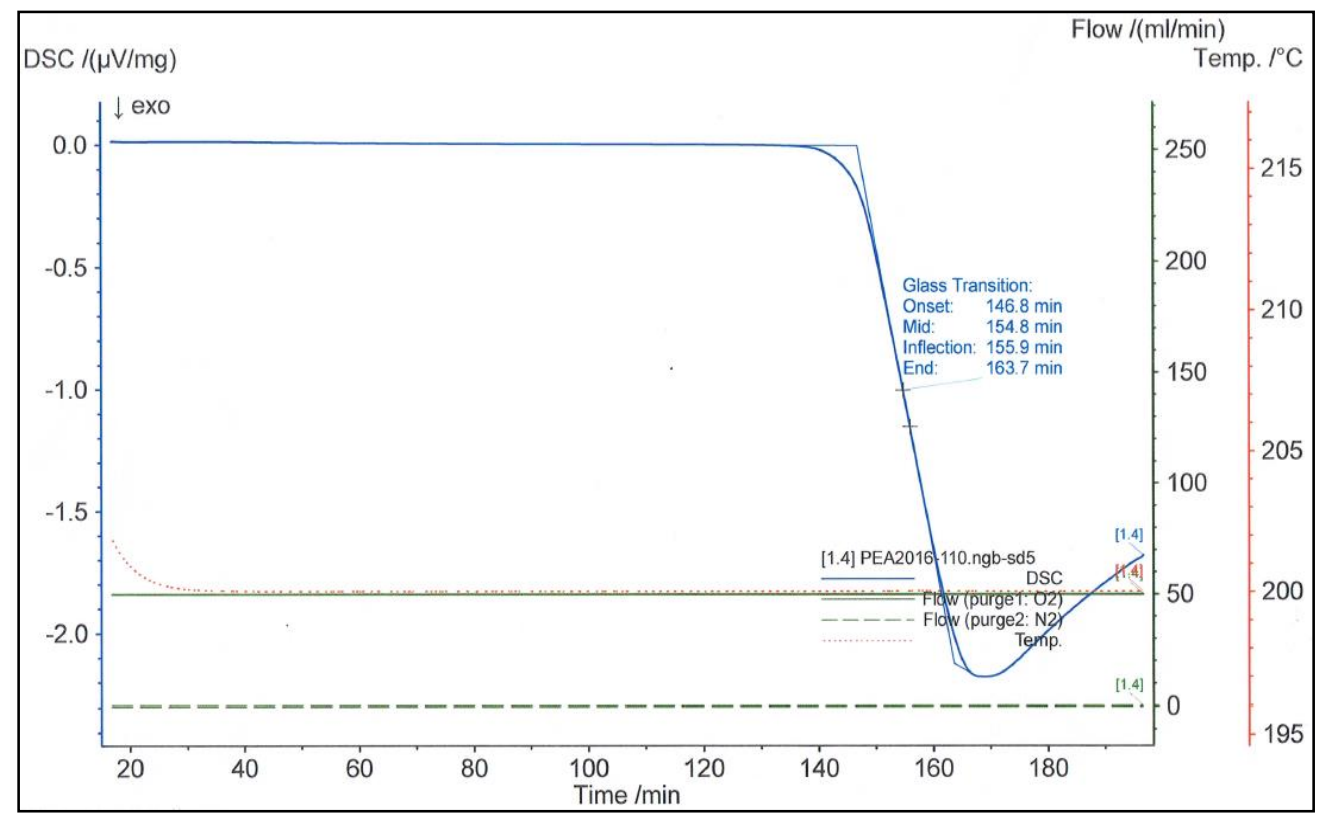

Figure 11: Glass transition time for PE-A samples

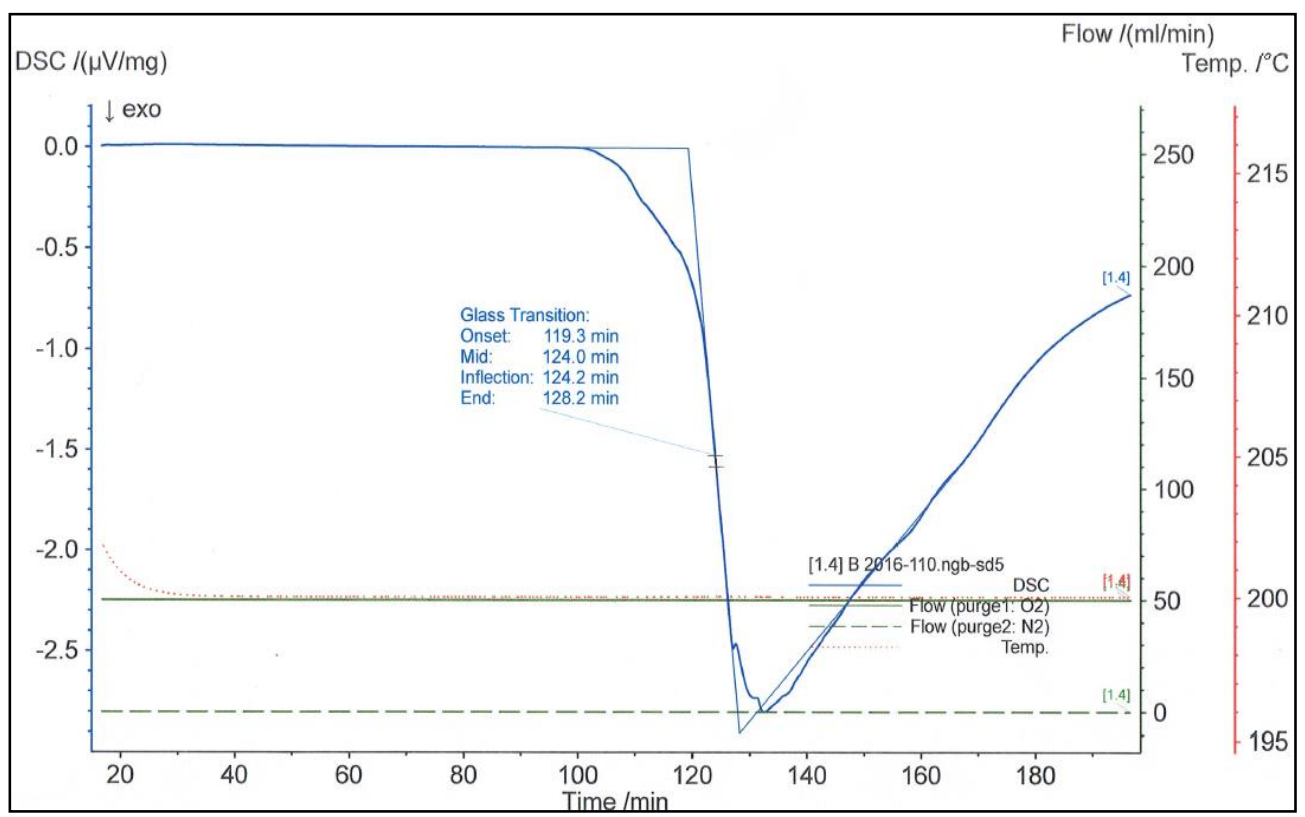

Figure 12: Glass transition time for PE-B samples 


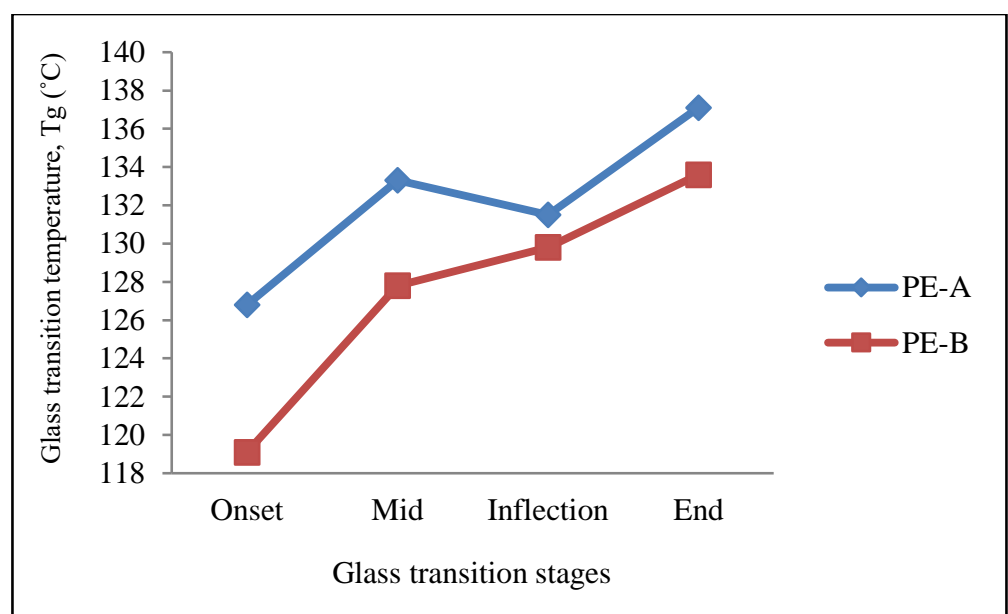

Figure 13: Glass transition temperatures for PE-A and PE-B at different stages

During the service, water leakage and consumption reaction may occur which causes depletion of antioxidants. Therefore, to protect the pipes from thermal oxidation, the OIT test was conducted to monitor this case. The level of the remaining antioxidants in the pipe is measured through OIT testing. The exothermic reaction or as called the onset to oxidation will be recorded as a OIT (in minutes) during the test. From the OIT figures this value was determined by drawing a tangent to the exotherm at its maximum point [9]. Figures 14 and 15 show the OIT for PE-A (136.3 min) and PE-B (102.7 min) respectively. According to ISO $4427-2$, this time for test temperature of $200^{\circ} \mathrm{C}$ is $\geq 20 \mathrm{~min}$. So, both pipes are within the standards.

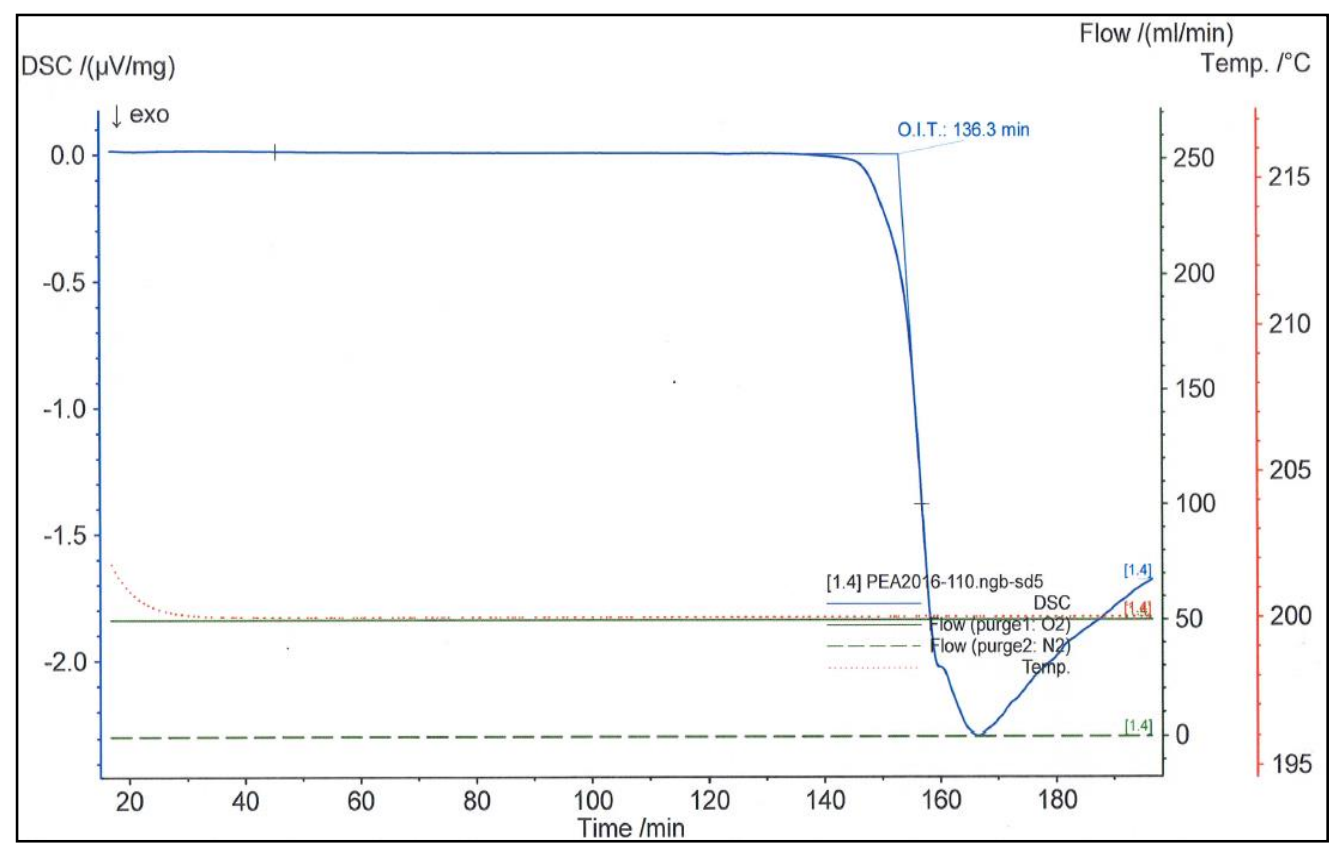

Figure 14: Oxidation induction time for PE-A samples 


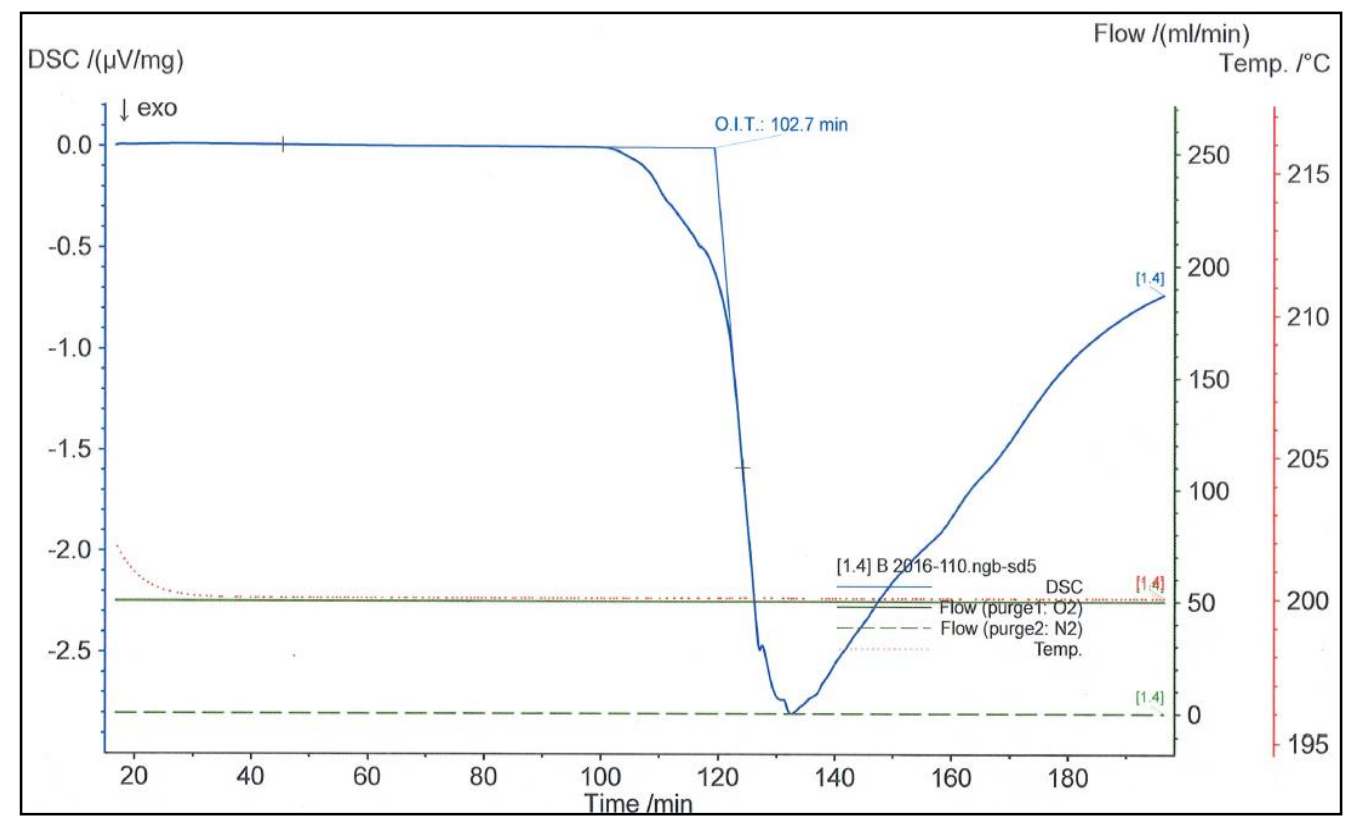

Figure 15: Oxidation induction time for PE-B samples

\section{CONCLUSION}

Mechanical properties and response to the heat of PE pipes utilized in potable water distribution networks in Kurdistan have been investigated experimentally. Both tensile test and DSC were used. Two sets of samples from two PE pipe manufacturers were tested. The concluded points are summarized as follows:

1. The ultimate tensile strength value was $26.75 \mathrm{MPa}$ for the pipe from manufacturer B corresponding to $18 \%$ strain. While the value of strength decreased to $24.59 \mathrm{MPa}$ for manufacturer A with $20 \%$ corresponding strain.

2. The maximum elongation at break was $628.14 \%$ for the pipe of manufacturer $A$.

3. The maximum percentage for strain at break was $507.79 \%$ for the pipe of manufacturer A.

4. The glass transition of pipe $\mathrm{A}$ was above the value of pipe $\mathrm{B}$, where the recorded maximum temperature was $126.8^{\circ} \mathrm{C}$ at onset and $137.1^{\circ} \mathrm{C}$ at the end.

5. The range of oxidation induction time was from $136.3 \mathrm{~min}$ to $102.7 \mathrm{~min}$ for pipes A and $B$ respectively.

\section{ACKNOWLEDGMENTS}

The experimental test of this work was conducted at Sulaimani Civil Construction Laboratory. The author extends special thanks to Engr. Aryan Wahid for his help with the testing.

\section{REFERENCE}

[1] D. Brocca, E. Arvin, and H. Mosbæk, "Identification of organic compounds migrating from polyethylene pipelines into drinking water," Water Res., vol. 36, no. 15, pp. 3675-3680, Sep. 2002.

[2] S. Kanagaraj, F. R. Varanda, T. V. Zhil'tsova, M. S. A. Oliveira, and J. A. O. Simões, "Mechanical properties of high density polyethylene/carbon nanotube composites," Compos. Sci. Technol., vol. 67, no. 15-16, pp. 3071-3077, Dec. 2007.

[3] H. Fang, P. Tan, B. Li, K. Yang, and Y. Zhang, "Influence of Backfill Compaction on Mechanical Characteristics of High-Density Polyethylene Double-Wall Corrugated Pipelines," Math. Probl. Eng., vol. 2019, 2019

[4] T. Bachir-Bey and N. Belhaneche-Bensemra, "Investigation of Polyethylene Pipeline Behavior after 30 
Years of Use in Gas Distribution Network," J. Mater. Eng. Perform., vol. 29, pp. 6652-6660, 2020.

[5] A. Frank, G. Pinter, and R. W. Lang, "Prediction of the remaining lifetime of polyethylene pipes after up to 30 years in use," Polym. Test., vol. 28, no. 7, pp. 737-745, Oct. 2009.

[6] R. Khelif, A. Chateauneuf, and K. Chaoui, "Reliability-based assessment of polyethylene pipe creep lifetime,” Int. J. Press. Vessel. Pip., vol. 84, no. 12, pp. 697-707, Dec. 2007.

[7] K. Leskovics, M. Kollár, and P. Bárczy, "A study of structure and mechanical properties of welded joints in polyethylene pipes," Mater. Sci. Eng. A, vol. 419, no. 1-2, pp. 138-143, Mar. 2006.

[8] C. Zhao, H. Qin, F. Gong, M. Feng, S. Zhang, and M. Yang, "Mechanical, thermal and flammability properties of polyethylene/clay nanocomposites," Polym. Degrad. Stab., vol. 87, no. 1, pp. 183-189, Jan. 2005.

[9] E. M. Hoàng and D. Lowe, "Lifetime prediction of a blue PE100 water pipe," Polym. Degrad. Stab., vol. 93, no. 8, pp. 1496-1503, Aug. 2008.

[10] J. M. L. Reis, L. J. Pacheco, and H. S. da C. Mattos, "Tensile behavior of post-consumer recycled highdensity polyethylene at different strain rates," Polym. Test., vol. 32, no. 2, pp. 338-342, 2013.

[11] D. Castagnetti, G. Scir Mammano, and E. Dragoni, "Effect of chlorinated water on the oxidative resistance and the mechanical strength of polyethylene pipes," Polym. Test., vol. 30, no. 3, pp. 277-285, May 2011.

[12] H. Teodorescu-Draghicescu, D. Scarlatescu, S. Vlase, M. L. Scutaru, and C. Nastac, "Advanced highdensity polyethylene used in pipelines networks," Procedia Manuf., vol. 22, pp. 27-34, 2018.

[13] Y. Wu, X. You, and S. Zha, "Mechanical behavior analysis of buried polyethylene pipe under land subsidence," Eng. Fail. Anal., vol. 108, p. 104351, 2020.

[14] Y. Wang, H. Lan, and T. Meng, "Lifetime prediction of natural gas polyethylene pipes with internal pressures," Eng. Fail. Anal., vol. 95, pp. 154-163, 2019.

[15] Y. Wu, Y. Zhang, S. Zha, and G. Qin, "Strength Analysis of Buried Polyethylene Pipeline Under Ground Subsidence Considering Multivariate Influence,” J. Press. Vessel Technol., vol. 142, no. 4, pp. 1-10, 2020.

[16] T. R. Kratochvilla, A. Frank, and G. Pinter, "Determination of slow crack growth behaviour of polyethylene pressure pipes with cracked round bar test," Polym. Test., vol. 40, pp. 299-303, Dec. 2014.

[17] M. Alexandre, P. Dubois, T. Sun, J. M. Garces, and R. Jérôme, "Polyethylene-layered silicate nanocomposites prepared by the polymerization-filling technique: synthesis and mechanical properties," Polymer (Guildf)., vol. 43, no. 8, pp. 2123-2132, Apr. 2002. 